Research Article

\title{
Load Carrying and Hydrostatic Performances of Innovative Encapsulated Anchorage System for Unbonded Single Strand
}

\author{
Min Sook Kim $\mathbb{D}^{1}$ and Young Hak Lee $\mathbb{D}^{2}$ \\ ${ }^{1}$ Research Fellow, Department of Architectural Engineering, Kyung Hee University, 1732 Deogyeong-daero, \\ Yongin, Republic of Korea \\ ${ }^{2}$ Professor, Department of Architectural Engineering, Kyung Hee University, 1732 Deogyeong-daero, Yongin, Republic of Korea \\ Correspondence should be addressed to Young Hak Lee; leeyh@khu.ac.kr
}

Received 21 June 2019; Revised 31 July 2019; Accepted 11 August 2019; Published 25 August 2019

Academic Editor: Dimitris Rizos

Copyright (C) 2019 Min Sook Kim and Young Hak Lee. This is an open access article distributed under the Creative Commons Attribution License, which permits unrestricted use, distribution, and reproduction in any medium, provided the original work is properly cited.

\begin{abstract}
A new anchorage system is proposed having a circular bearing plate and curvature between the bearing plate and the anchor head to improve stress concentration. A lid with a screw instead of the grouting method is also proposed to prevent moisture penetration. The details of the anchorage device have been chosen to reduce stress concentration based on the finite element analysis. Static load test, load transfer test, and hydrostatic test of fabricated devices were carried out according to ETAG 013 to evaluate the proposed design. As results, the anchorage slip and stabilization satisfied the recommendations of ETAG 013. The maximum load in the load transfer test was at least 1.1 times the ultimate tendon strength. The results of the hydrostatic test showed that the developed anchorage device is watertight to protect against corrosion. As a result of bursting force test, it was confirmed that the proposed anchorage device has more advantages than the conventional rectangular anchorage devices in terms of stress distribution.
\end{abstract}

\section{Introduction}

The concentrated prestressing force is transferred from the prestressing tendon onto the concrete via the anchorage system. Local cracking or failure may occur in the anchorage zone if the prestressed tendon induces compressive stress exceeding the compressive strength of the concrete. To prevent cracks and the local failure in the anchorage zone, additional reinforcement or an appropriate anchorage system should be applied based on the experimental and theoretical research studies.

Kwon et al. [1] proposed an anchorage device with lateral reinforcement to resist bursting stress and developed a modified equation of bearing capacity based on their experimental and analytical results. Walsh et al. [2] showed that posttensioning of the anchor or wedges plays a significant role in anchorage performance by controlling the stress transfer from the tendon to the anchor and, based on experimental results, proposed wedge details that can improve performance. Kim et al. [3] investigated the effects of steel fiber and steel reinforcements on the ultimate bearing strength of the local anchorage zone and compared the results of the experimental results with the design equation. Walsh and Kurama [4] reported that most tendon failures occur in cases where the first few full-depth wedge teeth grip the tendon at the anchor cavity and showed how the geometric properties of the wedges and anchors affect the ultimate tendon performance.

Cracks and local failure in the anchorage zone not only can reduce durability and structural capability but also can allow moisture to easily access tendon (ACI 423.4R [5]). The major cause of deterioration in the posttensioned concrete structures, which affects structural performance in terms of load-carrying capacity and serviceability, is the prestressing tendon corrosion. Many researchers have investigated that the cause of the prestressing tendon corrosion and its mechanism are affected by chloride and poor grouting in the sheaths. Schokker et al. [6] proposed optimum grouts for 
posttensioning based on the results of accelerated corrosion test. Minh et al. [7] investigated the influence of various degrees of grout filling of sheaths upon the corrosion of the prestressed tendons within them. They also performed a structural test to evaluate the deterioration in the loadcarrying capacity of the prestressed concrete beams due to corrosion. The test results showed that the ratio of grouting applied inside the sheath affects the load-carrying capacity. Li et al. [8] carried out a long-term experimental program to investigate the corrosion propagation of prestressing steel strands in the concrete. They reported that the corrosion rate of the prestressing tendon increases in a linear manner as the level of the applied stress increases. Wang et al. [9] investigated strand corrosion-induced concrete cracking experimentally and analytically. They proposed analytical model to predict the concrete cracking considering strand rust expansion ratio and the residual stiffness of the concrete. Dai et al. [10] proposed analytical model considering strand cross section reduction and bond degradation to predict the flexural capacity of the deteriorated prestressed concrete beams due to the corrosion.

Corrosion of the anchorage as well as tendon corrosion can also cause durability degradation of the posttensioned concrete members. Since the concrete cover of the pocket former is usually thinner than that of the prestressing tendon, the anchorage would be corroded prior to the prestressing tendons. In the unbonded posttensioned concrete structure, the prestressing tendons are protected with polyethylene sheaths while the anchorages are protected only with concrete cover. The corrosion of the anchorage is also nonnegligible because of corrosion failure. However, most of the research studies in terms of the corrosion of the posttensioned concrete structures have been focused on prestressing tendons. Only a few companies have developed encapsulated anchor systems (Sorkin [11] and Crigler and Hunsicker [12]). These systems include an encapsulation extending around a steel anchor body therein to prevent corrosion of metal components such as anchor plates.

Stress concentration and corrosion due to poor grouting and exposed bearing plate in the anchorage zone are problems to be solved in conventional anchorage systems. Therefore, it is necessary to develop an anchorage system capable of reducing stress concentration as well as improved water tightness. The aim of this research is to develop an anchorage system that is easy to install, while fulfilling the given requirements of structural capacity and water tightness. A newly developed anchorage system was analytically and experimentally investigated for the commercially available and popular unbonded single-strand tendon with $12.7 \mathrm{~mm}$ diameter.

This research consisted of three steps. In the first step, the finite element modelling and parametric study were performed to design and optimize the details of anchorage to reduce stress concentration and exercise its full capacity. In the second step, the anchorage device acceptance tests were conducted to prove that the proposed anchorage device was capable of load-carrying capacity and corrosion resistance. The tests included static load test, load transfer test, and hydrostatic test. Finally, a load transfer test was carried out to compare the bursting forces of the proposed anchorage devices with the conventional one.

\section{Design Concept}

The proposed anchorage system aims at improving the aforementioned three problems, stress concentration around the bearing plate, corrosion of the tendon due to poor grouting, and corrosion of the anchorage. For these purposes, a circular bearing plate, a pocket former without grouting, and noncorrosive pocket former wrapping anchor plate were developed.

A conventional unbonded single-strand tendon anchorage consists of a rectangular bearing plate and a cylindrical cavity, and its connection is reinforced with gussets as shown in Figure 1(a). This anchorage type usually causes the stress concentration in the gusset and edge of the plate, thereby reducing the transmission of tension from the tendon to the concrete members and possibly causing local cracks. The circular bearing plate was employed instead of a typical rectangular one. Herein, a new anchorage device consisting of a circular bearing plate and a cylindrical cavity is proposed as shown in Figure 1(b). In this proposed device, no gusset is required because the connection between the bearing plate and cavity is curved. The curved connection was adopted due to its efficiency in reducing the stress concentration that caused premature yield of anchor plate.

A pocket former is used to create a void in the concrete and is typically placed between the anchor and the structural form. The pocket is filled and finished with grouting material after posttensioning. If the grouting material does not sufficiently fill the space formed by the pocket former, this can form a path for moisture penetration. For this reason, the pocket former may cause the insufficient performance of water tightness. Therefore, a lid was chosen for its fast and easy installation process as well as improved water tightness. The proposed pocket former was designed to screw the lid and seal it after posttensioning without filling the grouting materials. Also, the pocket former was designed by inserting the circular bearing plate into a circular case made of noncorrosive and lightweight polyoxymethylene to prevent corrosion of the bearing plate. As shown in Figure 2(a), the developed anchorage has four major components: singlestrand tendon, wedge, circular bearing plate, and an anchorage case with a lid surrounding the bearing plate that functions as the pocket former. This anchorage system is assembled by screwing the lid after posttensioning as shown in Figures 2(b) and 2(c).

\section{Finite Element Analysis}

3.1. Finite Element Model. Finite element analysis consisted of two steps. The first step was to determine the details of the proposed anchorage device. The stress distribution of the proposed anchorage was compared with that of the conventional rectangular anchorage in the second step. The finite element model for determining the details of the circular bearing plate is shown in Figure 3. The finite element model for comparison of the stress distribution is shown in 


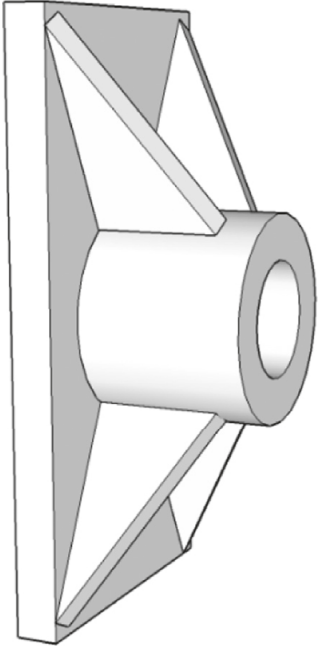

(a)

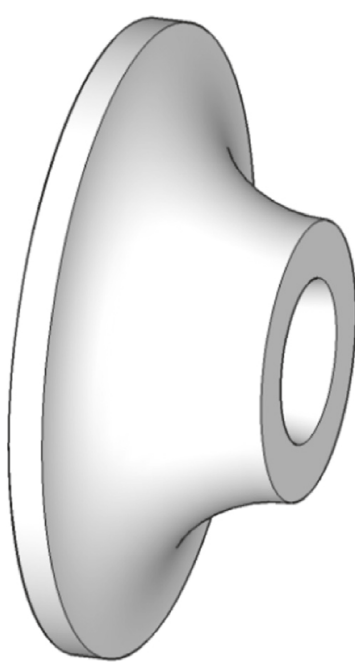

(b)

Figure 1: Anchorage devices: (a) conventional rectangular anchorage and (b) proposed circular anchorage.

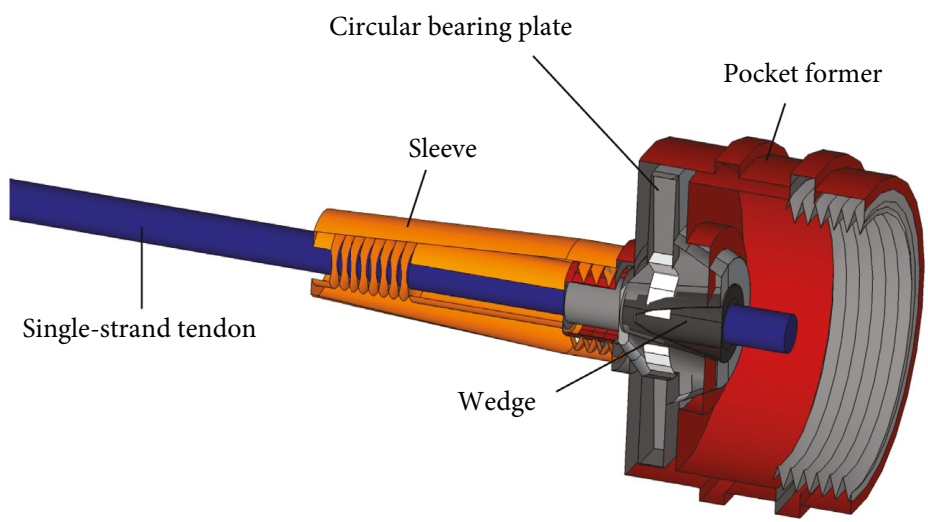

(a)
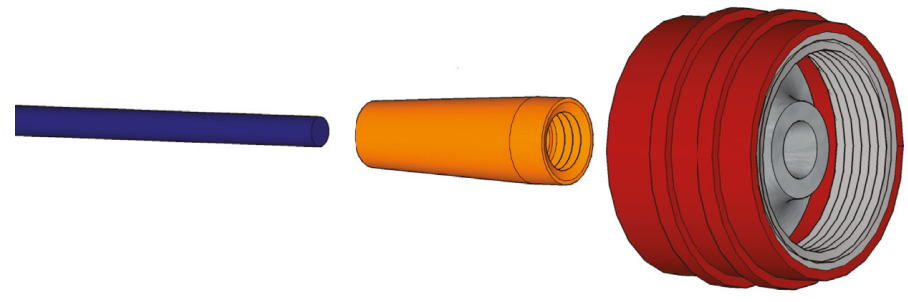

(b)

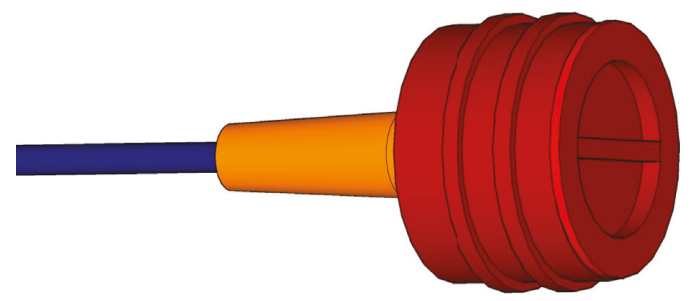

(c)

Figure 2: Proposed anchorage system: (a) section of anchorage, (b) before assembly, and (c) after assembly.

Figure 4. The commercial FE analysis software ANSYS 15.0 was employed to analyze the stress. A three-dimensional and eight-node solid element was applied to the model. For efficiency of analysis, a half symmetrical model was used for the analysis of anchorage zone. It was assumed that the anchorage device and the concrete were perfectly bonded in 


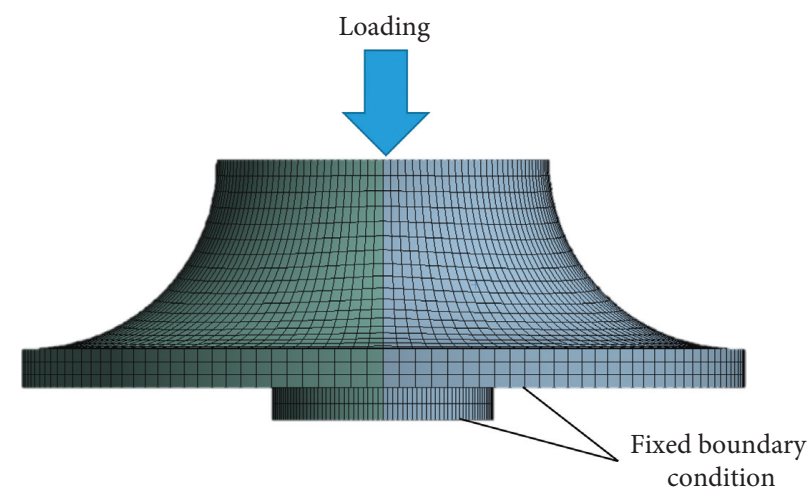

FIGURE 3: Finite element model of anchorage.
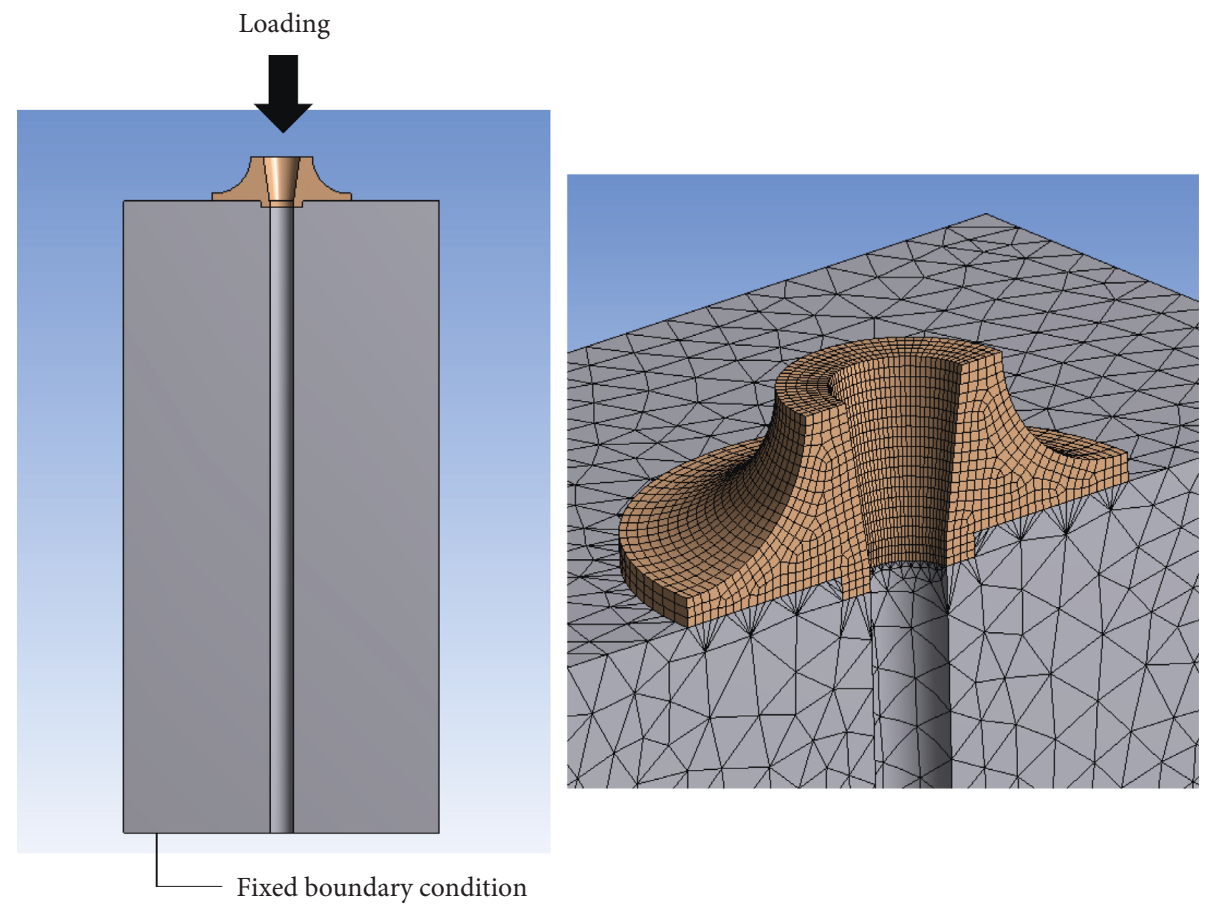

(a)

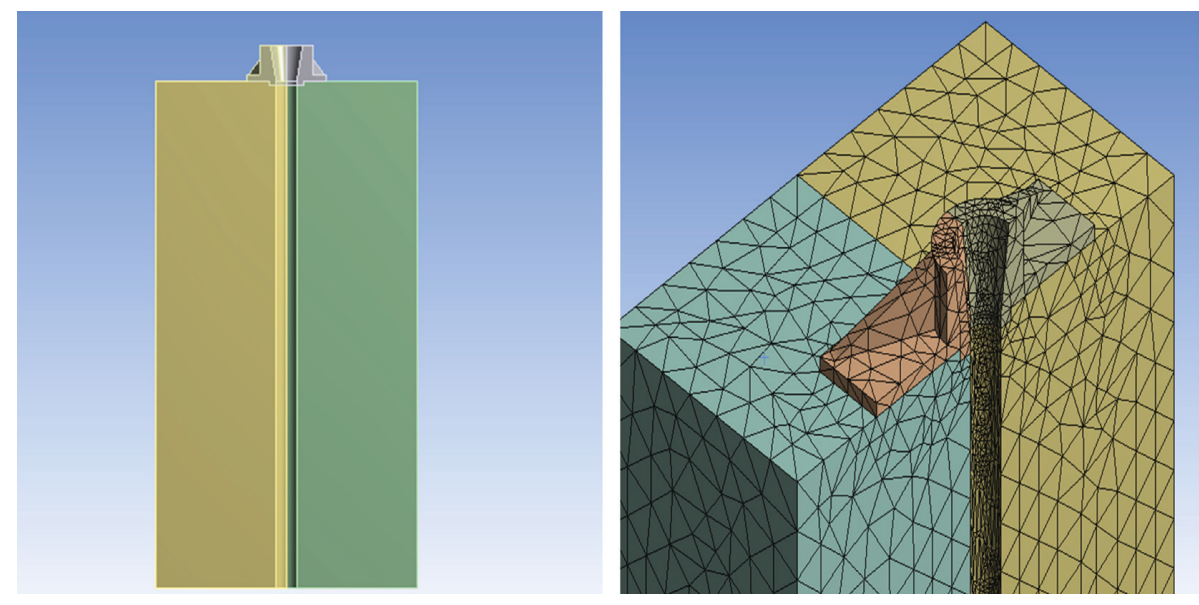

(b)

Figure 4: Finite element model for bursting stress analysis. Finite element model of (a) circular anchorage and (b) rectangular anchorage. 
the second step models. The bearing plate and concrete were modelled as isotropic materials. The yield strength and ultimate strength of the bearing plate were $320 \mathrm{MPa}$ and $500 \mathrm{MPa}$, respectively. The compressive strength of the concrete was $30 \mathrm{MPa}$. The material properties are listed in Table 1.

According to ETAG 013 [13], 95\% of the nominal ultimate load of single-strand tendon with $12.7 \mathrm{~mm}$ diameter was applied to the top of the anchorage, and the bottom surface had a fixed boundary condition in the analysis models.

\subsection{Determinations of the Details of the Proposed Circular} Anchorage Device. The diameter of the circular anchorage device was first determined to be $110 \mathrm{~mm}$ to have a similar bearing area as the conventional rectangular bearing plate to minimize the influence of the bearing plate area. The thickness of the anchor head, the cavity thickness, the radius of curvature between the cavity and the bearing plate, and the thickness of the bearing plate were determined through parametric analyses as indicated in Figure 5. The results of finite analysis are summarized in Table 2.

For the anchorage with a low radius of curvature, the stress was concentrated on the joint between the cavity and near the cavity. As the radius of curvature increased, the stress gradually spread to the bearing plate and the stress concentration was reduced as shown in Figure 6. As a result, the thickness of the bearing plate did not significantly affect the stress distribution. The dimensions of the anchorage were determined by combining the minimum stress values based on the results of the finite element analysis considering each parameter. The determined dimensions of the proposed anchorage are presented in Figure 7. The thickness of the anchor head was determined to be $5 \mathrm{~mm}$, the radius of curvature between the bearing plates and the cavity was $29 \mathrm{~mm}$, and the cavity thickness was $10 \mathrm{~mm}$, respectively. The thickness of the bearing plate was determined to be $6 \mathrm{~mm}$, which is the same as that of the conventional rectangular anchorage.

\subsection{Comparison of Stress Distribution in the Anchorage Zone.} Stress analysis for the anchorage zone was performed to compare the stress distributions of the proposed and existing anchorage devices. The diameter of circular anchorage was $110 \mathrm{~mm}$, and the cross-sectional dimension of rectangular anchorage was $75 \mathrm{~mm} \times 145 \mathrm{~mm}$. Both circular and rectangular anchors were modelled to be installed at the top of a concrete block. The size of each concrete block was determined by considering the area of the bearing plate in accordance with ETAG 013. The cross-sectional dimensions of the concrete block model were $250 \mathrm{~mm} \times 250 \mathrm{~mm} \times 500 \mathrm{~mm}$.

Figure 8 shows the distributions of stresses along with the tendon path where normalized stress and distance were employed. The normalized stress is the ratio of the compressive stress $\left(f_{0}\right)$ to bursting stress $\left(f_{\mathrm{b}}\right)$. The normalized distance is the ratio of distance from the bearing plate $(x)$ to the height of the cross section of the model $(h)$. In this study, the bursting stress of the long side of the rectangular anchor was measured larger than the short side in the rectangular anchorage model. The bursting stress of the long side of the rectangular anchor was compared with that of the circular anchorage model. The rectangular anchorage model had the maximum bursting stress of $6.6 \mathrm{MPa}$ at $20.8 \mathrm{~mm}$ from the anchorage, whereas the proposed anchorage model had the maximum bursting stress of $3.25 \mathrm{MPa}$ at $51.6 \mathrm{~mm}$ from the top of the block. In the rectangular anchorage model, the bursting stress converged to zero at $137 \%$ of the height of the member and in the proposed anchorage model at $136 \%$ of the height of the member. The results of the analysis showed that the bursting stress is better distributed in the proposed anchorage model than in the rectangular anchorage model.

\section{Experimental Program}

4.1. Proposed Anchorage Device Acceptance Test. The anchorage devices are classified into two categories: basic and special devices in the posttensioned concrete members according to the American Association of State Highway and Transportation Officials (AASHTO). The basic anchorage devices have rectangular bearing plates while the devices not using the rectangular bearing plates are defined as the special anchorage devices. The proposed anchorage device can be considered as a special device based on the AASHTO's guidelines. AASHTO requires acceptance tests for use of the special anchorage device [14]. The intension of the tests is to prove that the anchorage zone is capable of transferring forces to the concrete without bursting reinforcement. The purpose of this research is to propose the improved device for not only the structural performance but also the water tightness. Therefore, static load test, load transfer test, and hydrostatic test were included in this paper.

4.1.1. Static Load Test. The static load test was performed in order to evaluate the performance of the anchorage-tendon assembly and the tensile behavior of the tendon when the nominal ultimate load of a tendon was applied as a static load. ETAG 013 recommends that a static load test for single-strand tendon anchorage to be performed on five specimens. Therefore, five static load test specimens were fabricated and tested as shown in Figure 9. The five specimens were marked ST-A to ST-E. The compressive strength of the concrete was $30 \mathrm{MPa}$ and the yield strength of the anchorage was $490 \mathrm{MPa}$.

The anchorage was installed in a concrete block with dimensions $250 \mathrm{~mm} \times 250 \mathrm{~mm} \times 200 \mathrm{~mm}$. One concrete block was fixed to the rigid frame and the other block was fixed to the actuator as shown in Figure 10. According to ETAG 013, the free length of the tendon was set to be $3000 \mathrm{~mm}$. The displacements of the tendon were measured on core wire and one helical wire of the seven wires. To measure the displacements of wedges and tendons, LVDTs were installed at the ends of the tendon. A load of $80 \%$ of the ultimate strength of the tendon was applied using the actuator. The assembled wedges and tendon in the anchorage device under the test were stabilized while maintaining the load for one hour. The tendon should be settled to the wedge and the wedge should be settled to the anchorage. The 
TABle 1: Material properties for analytical model.

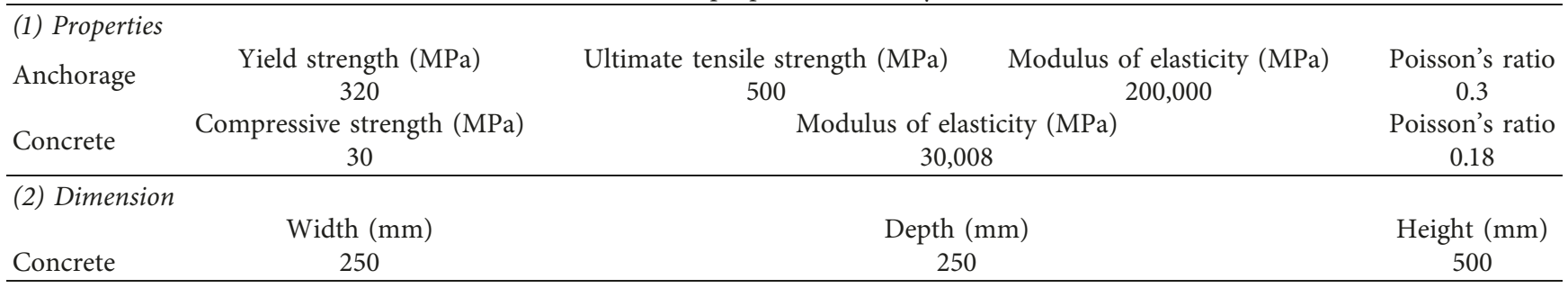

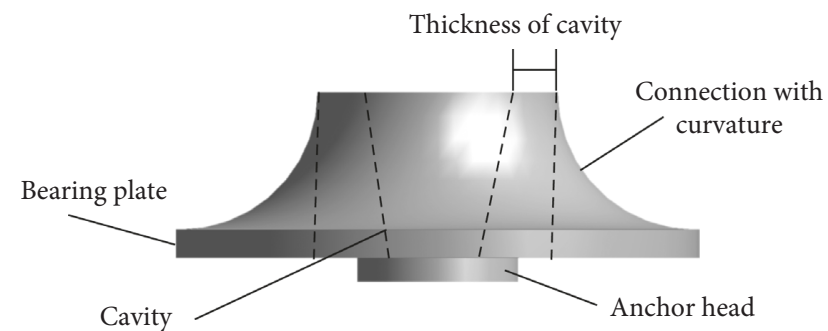

FIGURE 5: Components of the proposed circular bearing plate.

TABLE 2: Parametric analysis results.

(1) The thickness of the anchor head

\begin{tabular}{|c|c|c|c|c|c|}
\hline $\begin{array}{l}\text { Dimension } \\
(\mathrm{mm})\end{array}$ & 5 & 10 & 15 & 20 & 25 \\
\hline $\begin{array}{l}\text { Max stress } \\
(\mathrm{MPa})\end{array}$ & 198.45 & 250.64 & 347.07 & 382.92 & 401.28 \\
\hline ocation of ma & & $\mathrm{tt}$ & tor & ce of & \\
\hline
\end{tabular}

(2) Thickness of the wedge cavity

Dimension

$(\mathrm{mm})$

Max stress

$(\mathrm{MPa})$

$\begin{array}{llll}6 & 7 & 8 & 9\end{array}$

10

Location of max

$\begin{array}{llll}198.45 & 189.76 & 182.69 & 176.32\end{array}$

170.93

stress

Exterior upper face of wedge cavity

(3) Radius of curvature between the cavity and the bearing plate Dimension

$(\mathrm{mm})$

$\begin{array}{lllll}5 & 10 & 15 & 20 & 25\end{array}$ 29

Max stress

$(\mathrm{MPa})$

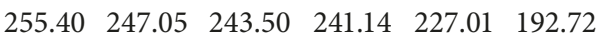

Location of max Connection of wedge Exterior upper face of stress cavity and plate wedge cavity

(4) Thickness of the bearing plate

Dimension

$(\mathrm{mm})$

Max stress

$(\mathrm{MPa})$

$\begin{array}{llll}4 & 5 & 6 & 7\end{array}$

8

Location of max

stress

$\begin{array}{lllll}198.59 & 198.4 & 198.54 & 198.47 & 198.75\end{array}$

Interior face of cavity

ultimate load was then evaluated by increasing the load until the tendon was ruptured.

4.1.2. Load Transfer Test. The objective of the load transfer test was to evaluate the transfer of compressive stress to the concrete member through the anchorage. The load transfer test was conducted according to ETAG 013. ETAG 013 recommends that a load transfer test for single-strand tendon anchorage to be performed on four specimens. Therefore, four specimens each containing the proposed anchorage were fabricated as shown in Figure 11.

The four specimens were marked LT-A to LT-D. The compressive strength of the concrete was $30 \mathrm{MPa}$, and the yield strength of the anchorage was $490 \mathrm{MPa}$. The crosssectional dimensions were set as $250 \mathrm{~mm}$ considering the size of $110 \mathrm{~mm}$ of the anchorage and minimum edge clearances of $70 \mathrm{~mm}$. Because the height of the specimen shall be at least twice longer of the two side lengths, the height of the specimens was set as $600 \mathrm{~mm}$.

To satisfy the reinforcement guidelines in ETAG 013, two longitudinal rebars of diameter $10 \mathrm{~mm}$ were placed and four stirrups of $10 \mathrm{~mm}$ diameter at a spacing of $160 \mathrm{~mm}$ were arranged. Also, a U-shaped reinforcement was installed in each specimen to resist bursting stress. The location of the reinforcement against bursting stress was determined to be the position at which the maximum bursting stress occurred in the finite element analysis. The load was applied to each specimen using a universal testing machine as shown in Figure 12.

The load was increased gradually in steps as $20 \%, 40 \%$, $60 \%$, and $80 \%$ of the ultimate strength of the tendon. After reaching the $80 \%$ of the ultimate strength of the tendon, at least ten load cycles were applied over the range between $12 \%$ and $80 \%$ of the ultimate strength. The crack width and strain were measured by using a gauge attached to the surface of the specimen. The measured strains and crack widths were utilized to determine the stability criteria of equations (1) and (2) as suggested in ETAG 013. The load was increased until the specimen failed after the stabilization process.

$$
\begin{gathered}
w_{n}-w_{n-4} \leq \frac{1}{3}\left(w_{n-4}-w_{0}\right), \quad n \geq 10, \\
\varepsilon_{n}-\varepsilon_{n-4} \leq \frac{1}{3}\left(\varepsilon_{n-4}-\varepsilon_{0}\right), \quad n \geq 10,
\end{gathered}
$$

where $w_{n}$ is the crack width and $\varepsilon_{n}$ is the longitudinal and transverse strain, and $n$ is the number of loading cycles.

4.1.3. Hydrostatic Test. The hydrostatic test was performed in order to evaluate the water tightness of the proposed anchorage device. Tests were performed according to PostTensioning Institute (PTI [15]) and ACI 423 [16] requirements for the hydrostatic test of encapsulated 


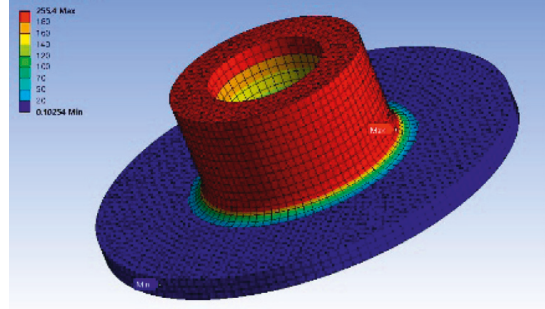

(a)

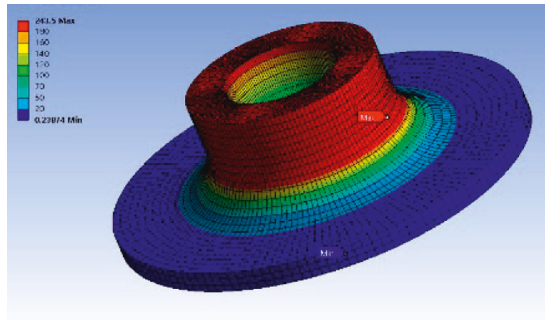

(c)

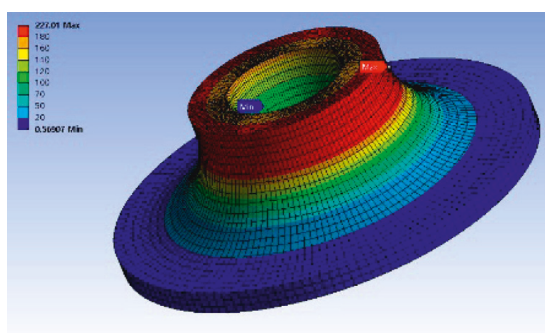

(e)

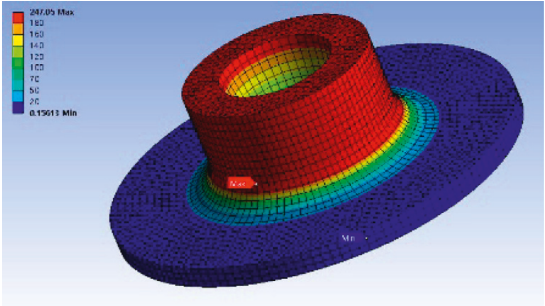

(b)

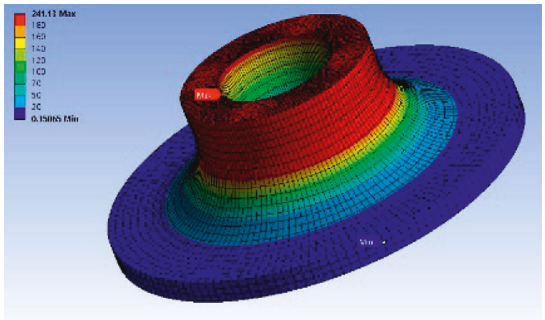

(d)

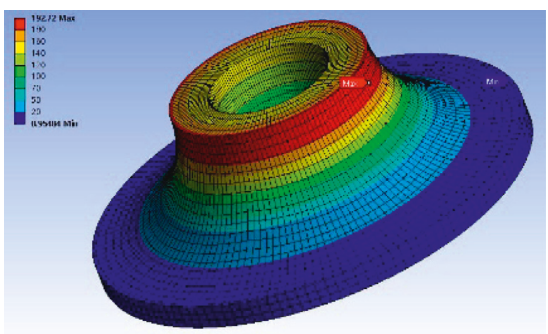

(f)

Figure 6: Equivalent stress distribution of the developed anchorage according to the radius of curvature between the cavity and the bearing plate. Curvature: (a) $5 \mathrm{~mm}$, (b) $10 \mathrm{~mm}$, (c) $15 \mathrm{~mm}$, (d) $20 \mathrm{~mm}$, (e) $25 \mathrm{~mm}$, and (f) $29 \mathrm{~mm}$.

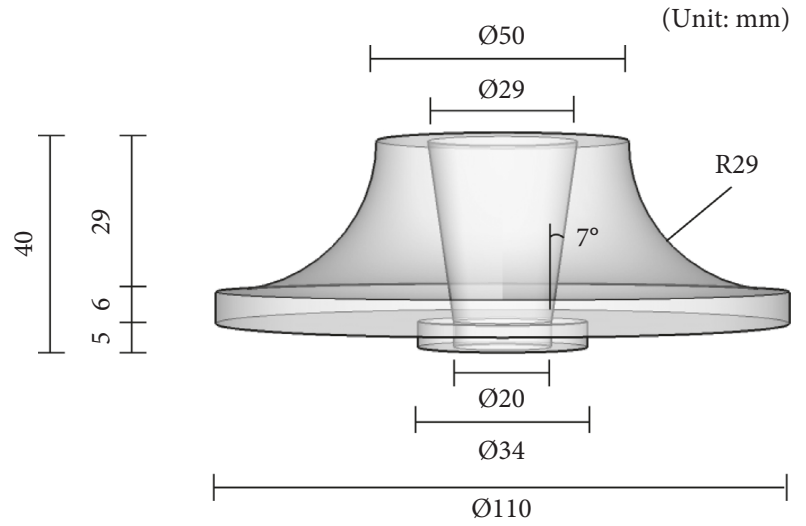

FIGURE 7: Details of the proposed anchorage.

anchorage systems. The required number of specimens for the hydrostatic test is not specified in PTI and ACI 423. For this test, three specimens were manufactured. ACI 423 specifies the minimum pressure of $8.6 \mathrm{kPa}$ for hydrostatic test. To maintain this pressure, one water tank was utilized as shown Figure 13. After the 24-hour hydrostatic test, the specimens were collected from the water tank, disassembled, and checked for water intrusion. The water contained red dye to clearly confirm the penetration of moisture.

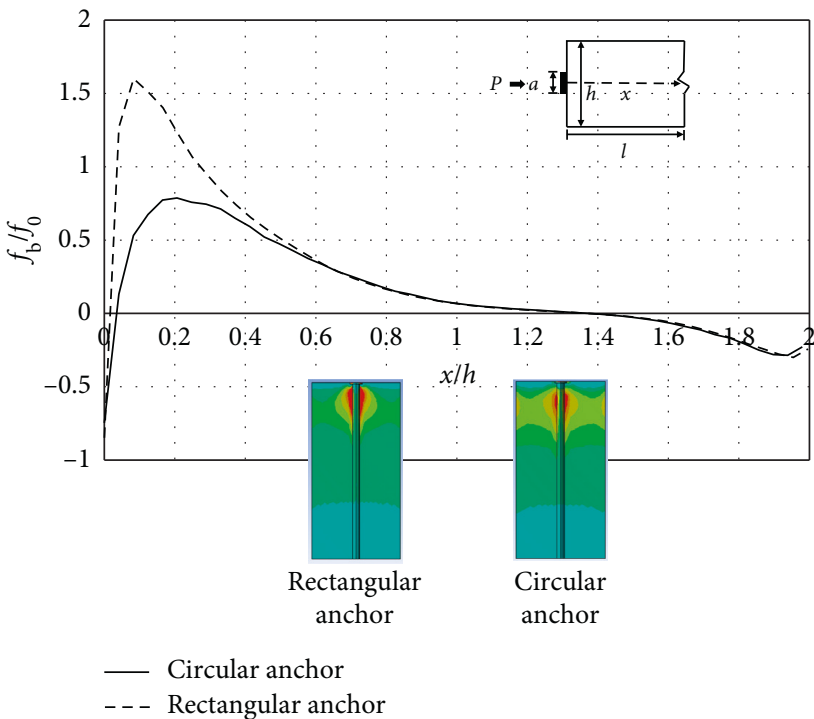

Figure 8: Bursting stress comparison between the rectangular anchor and the developed circular anchor.

4.2. Bursting Strength Test. To compare the bursting strength and structural behavior of the proposed and conventional anchorage devices, the load transfer test was conducted. The 


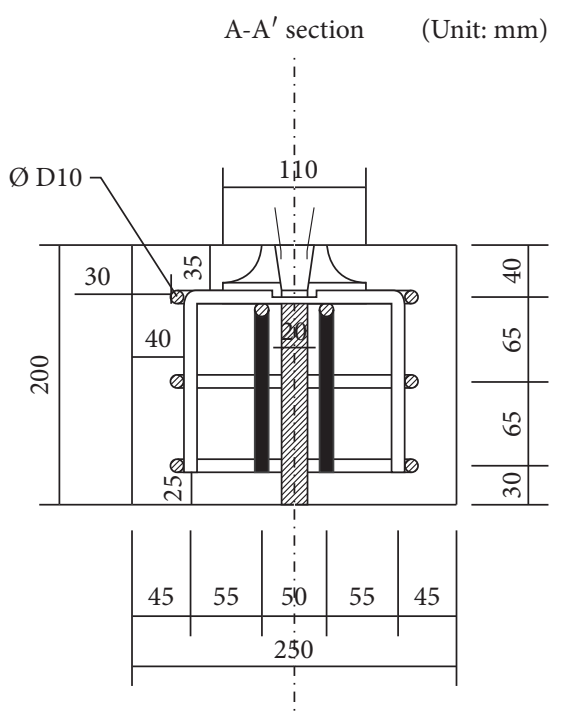

(a)

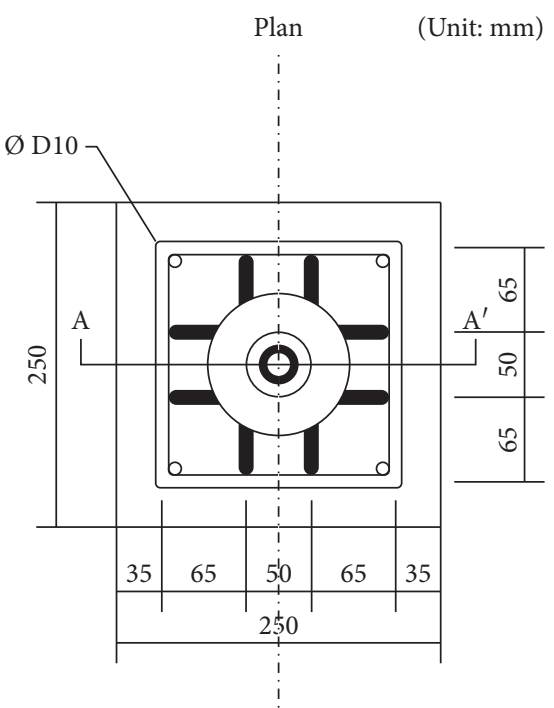

(b)

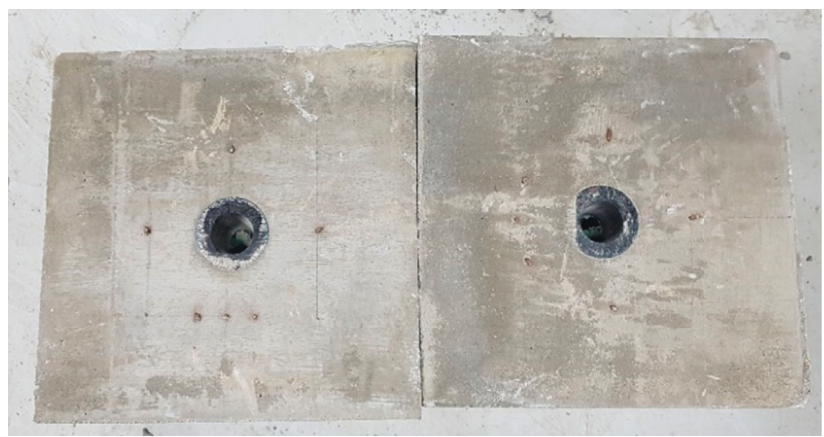

(c)

FIgURE 9: Detail of static load test specimens.

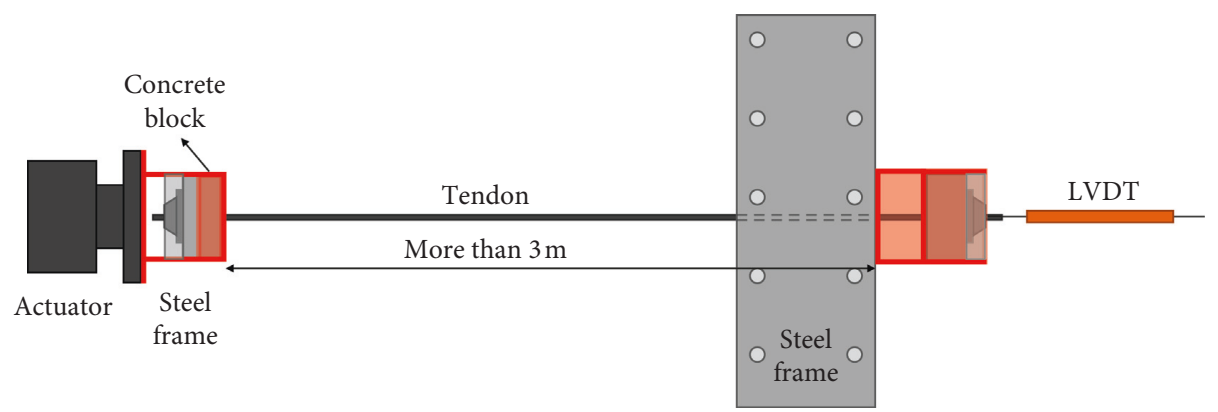

(a)

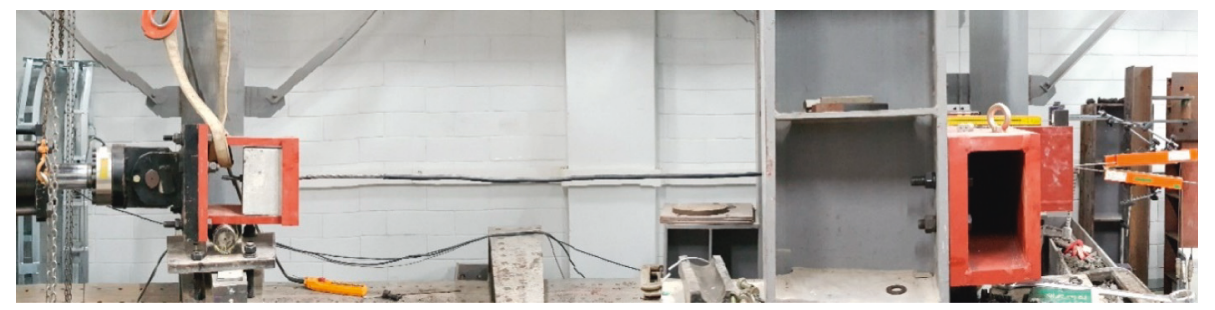

(b)

Figure 10: Static load test setup: (a) schematic test setup and (b) a photograph of the test setup. 


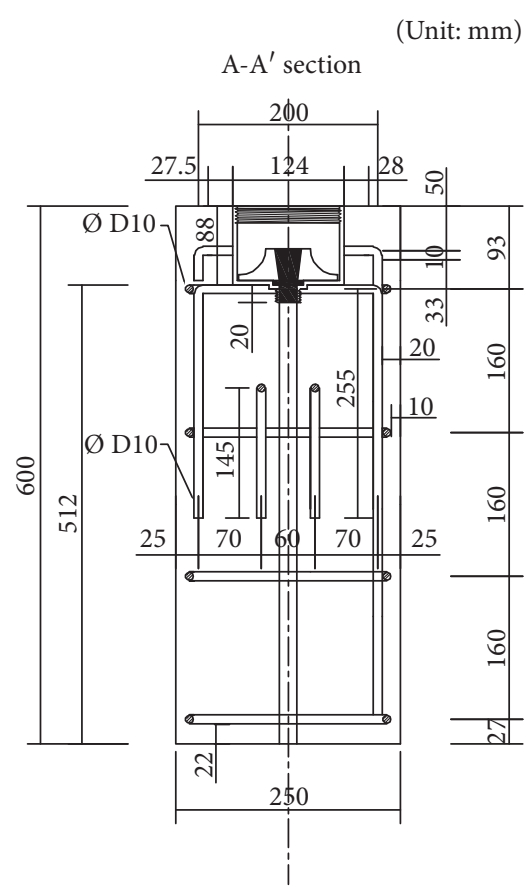

(a)

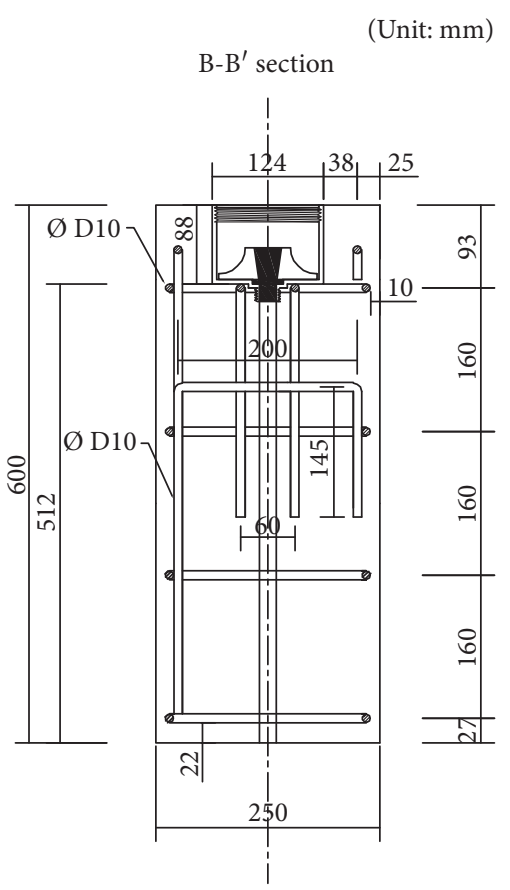

(b)

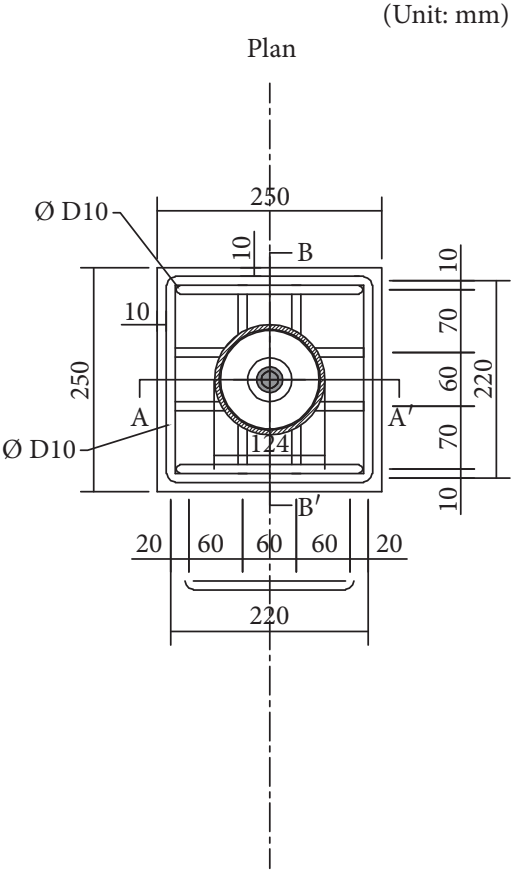

(c)

Figure 11: Detailed dimensions of the load transfer test specimen.

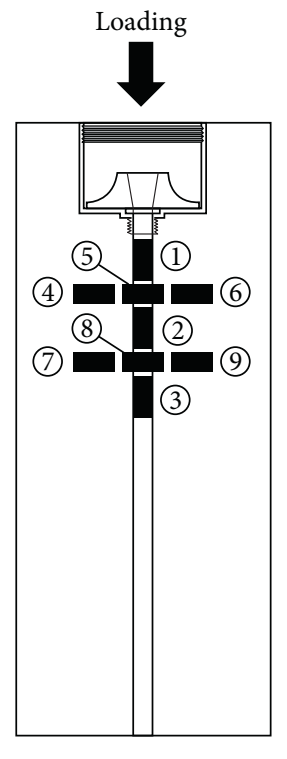

Gauge

(a)

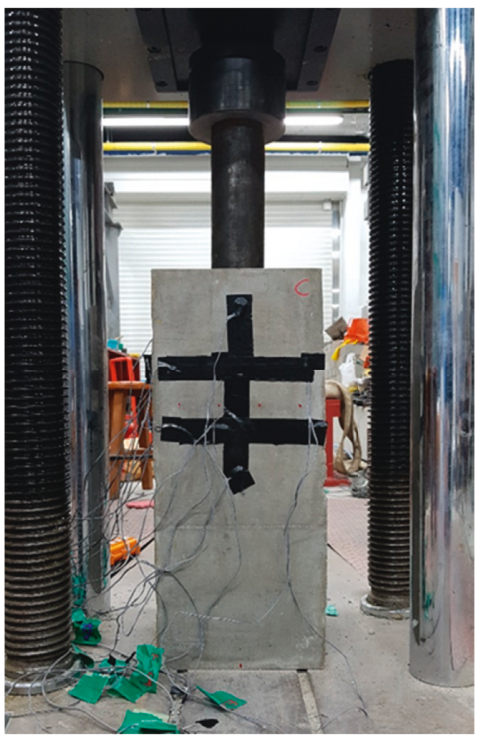

(b)

FIgURE 12: Load transfer test setup: (a) schematic test setup and (b) a photograph of the test setup.

test specimens were designed in the same way as the load transfer of the acceptance test. Two specimens each containing the proposed and conventional rectangular anchorage device were fabricated as shown in Figure 14.
The strains were measured by using a gauge as shown in Figure 14. In order to prevent detachment of gauges due to concrete cracks, a rebar with a diameter of $8 \mathrm{~mm}$ was arranged along the tendon path inside the concrete 


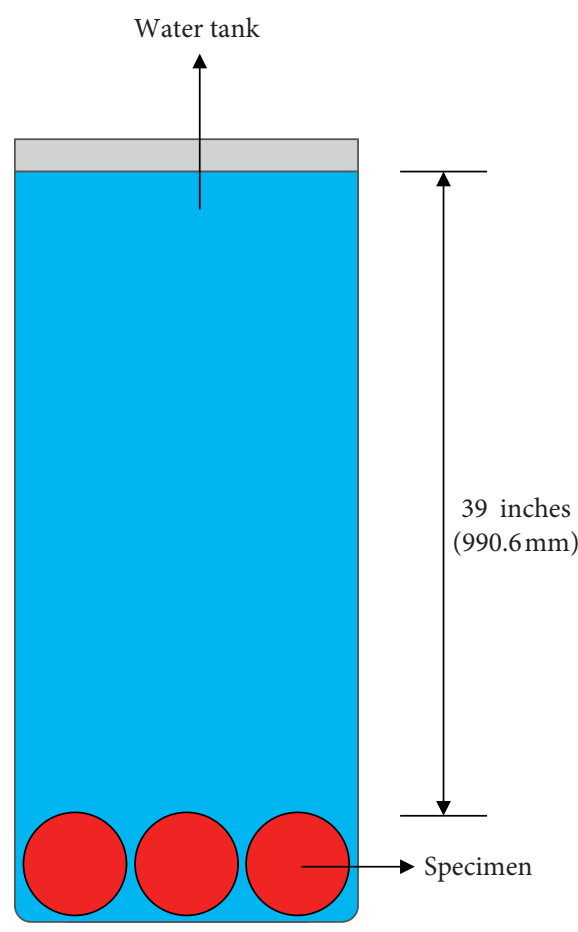

(a)

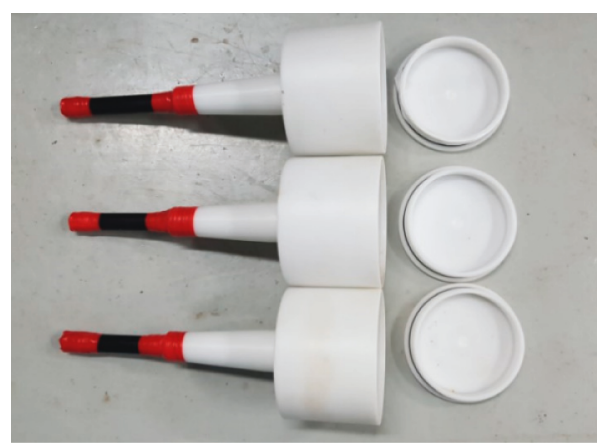

(b)

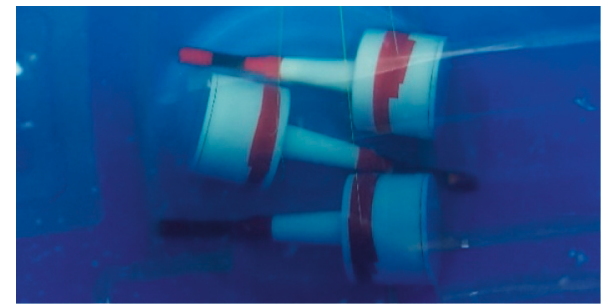

(c)

Figure 13: Hydrostatic test setup: (a) test apparatus, (b) before hydrostatic test, and (c) water tank containing specimens.

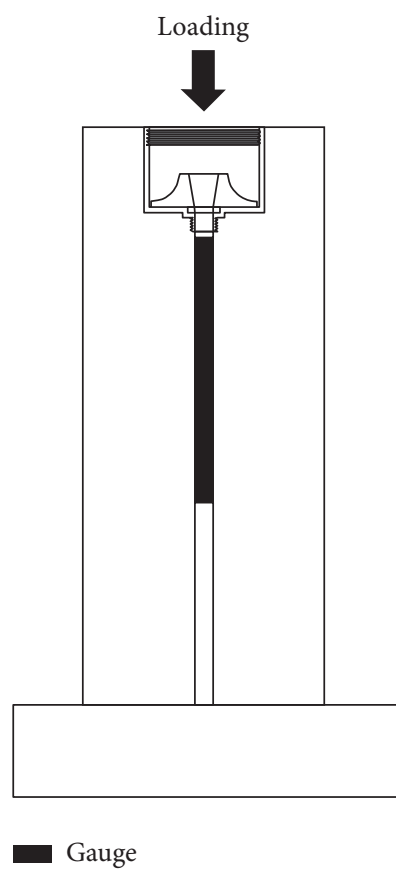

(a)

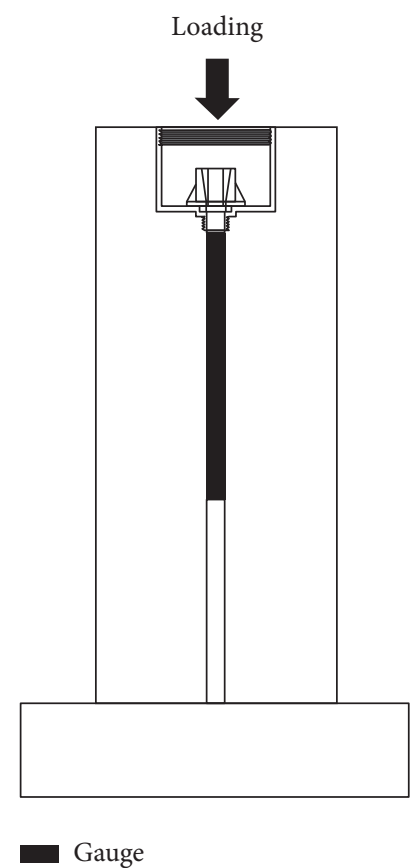

(b)

FIGURE 14: Bursting test setup: (a) circular anchorage and (b) rectangular anchorage.

TABLE 3: Ultimate load and failure mode in static load test.

\begin{tabular}{|c|c|c|c|c|}
\hline Specimen & $0.95 F_{p k}$ & Ultimate strength of tendon $(\mathrm{kN})$ & Anchorage slip (mm) & Failure mode \\
\hline ST-A & & 250.10 & 2.4 & \\
\hline ST-B & & 243.29 & 3.2 & \\
\hline ST-C & $245 \mathrm{kN}$ & 221.44 & 2.7 & Tendon failure \\
\hline ST-D & & 246.55 & 2.9 & \\
\hline ST-E & & 243.29 & 2.8 & \\
\hline
\end{tabular}




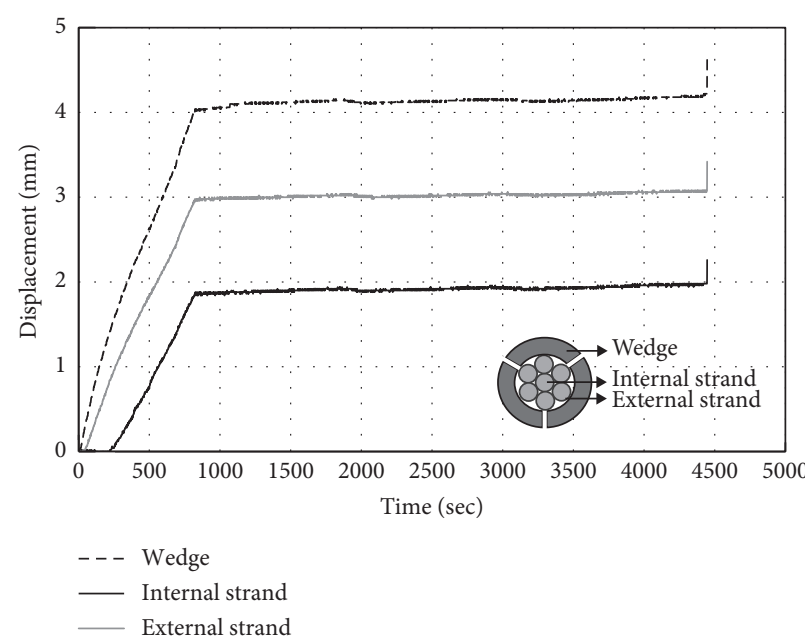

(a)

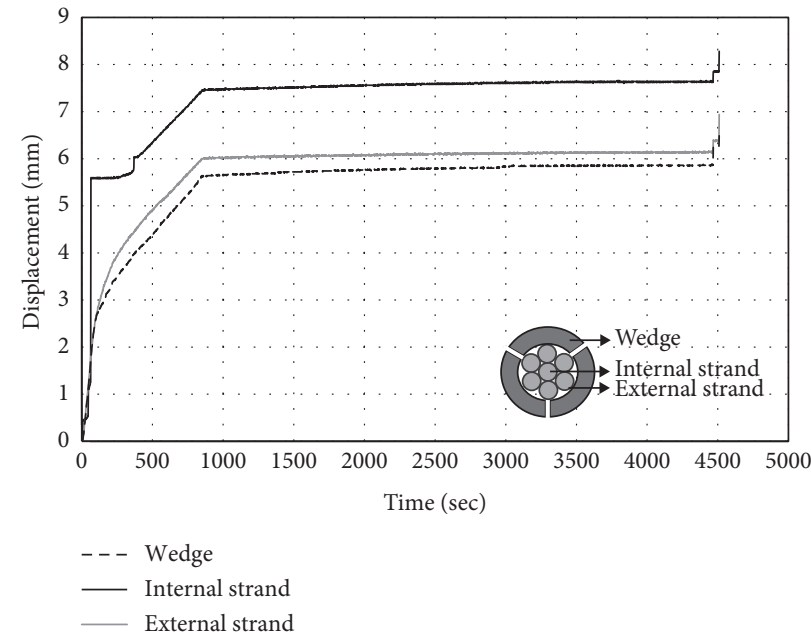

(c)

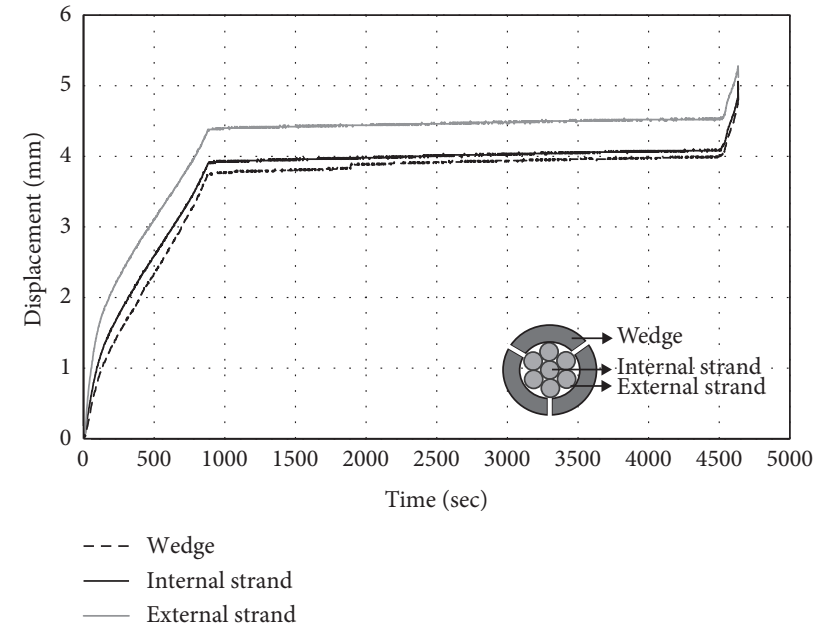

(b)

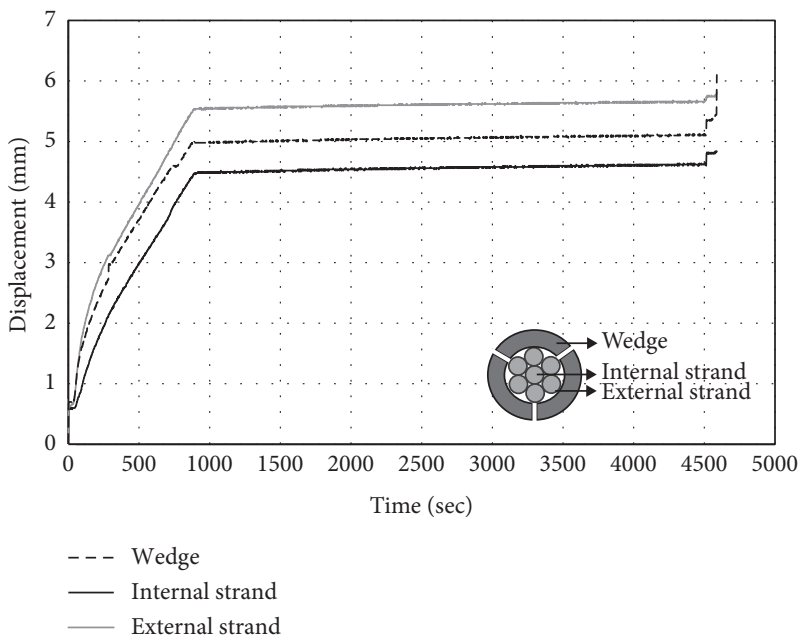

(d)

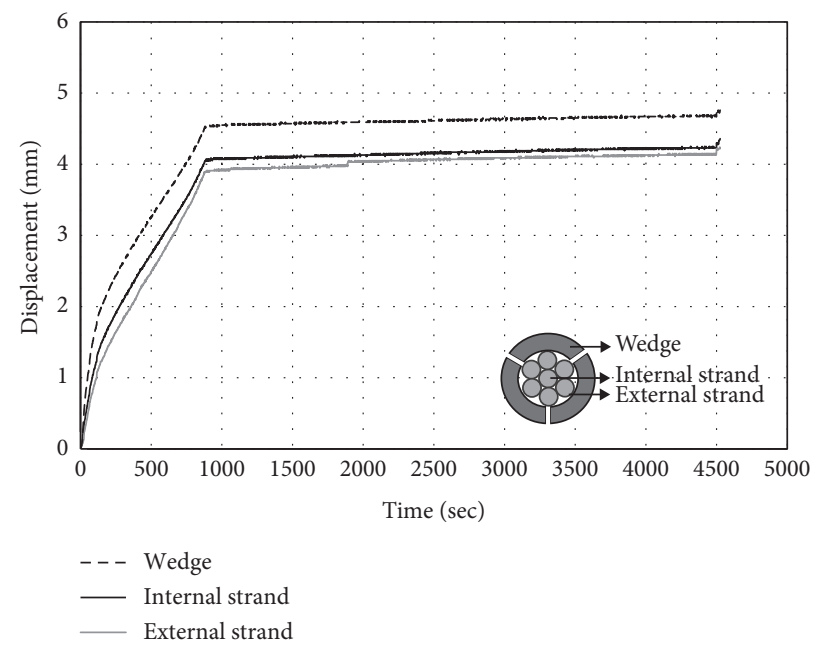

(e)

FIGURE 15: Displacements of strands and wedges during static load test: (a) ST-A, (b) ST-B, (c) ST-C, (d) ST-D, and (e) ST-E. 
specimen, and the gauges were attached to the rebars. The load was applied to the anchorage device until the specimen was failed.

\section{Experimental Results and Discussion}

\subsection{Proposed Anchorage Device Acceptance Test}

5.1.1. Static Load Test. The maximum load of each specimen is summarized in Table 3. The final failure occurred in the free length from the anchorage zone.

The maximum load of the specimens except one specimen was approximately $245 \mathrm{kN}$, which was $95 \%$ of the ultimate strength of the tendon. The average anchorage slip was measured to be $2.8 \mathrm{~mm}$. This value satisfies the recommendation of ETAG that the slip shall not exceed $5 \mathrm{~mm}$. The displacements of the wedge and tendon over time are presented in Figure 15. The displacements of each specimen stabilized within 30 minutes, meeting the ETAG stabilization criterion. The test results show that the anchorage device has sufficient ductility prior to fracture. Also, the assembly of the tendon and wedge in the anchorage was stable.

5.1.2. Load Transfer Test. All specimens were loaded until failure to measure their ultimate load-carrying capacities. Initial cracks occurred in the longitudinal direction of each specimen. Crack developments were observed in each specimen as the load increased and the specimens failed as shown in Figure 16. Figure 17 shows the relations of strain versus time for all specimens.

The maximum load and strains are provided in Table 4. The maximum loads ranged between 686 and $833 \mathrm{kN}$, which satisfied the ETAG 013 suggestion of $110 \%$ of ultimate tendon strength.

Based on the strain results, the stabilization criterion was satisfied in the 11th to 14th loading cycles. The anchorage was removed from each specimen to observe its deformation after the test. As shown in Figure 18, no large deformation in the anchorage was observed.

5.1.3. Hydrostatic Test. After the hydrostatic test of 24 hours, each anchorage device was collected from the water tank. Figure 19 shows the disassembled tested anchorage devices. All surface moisture on the anchorage device was removed, and the anchorage device was disassembled to confirm moisture penetration to the inside. No water or red dye was observed inside the anchorage devices. Also, no moisture was observed between the bearing plate and the wedge because of the superior water tightness of encapsulated anchorage system. The results satisfied the water tightness conditions of both PTI and ACI 423.

5.2. Ultimate Strength Behavior. The crack and failure patterns of the specimens with the conventional and proposed anchorage devices were similar as shown in Figure 20.

The first cracks occurred and developed forming longitudinal cracks along the tendon path. As the load increased, the inclined cracks appeared and spread to the side

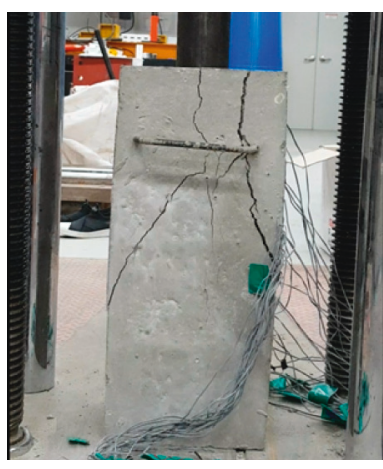

(a)

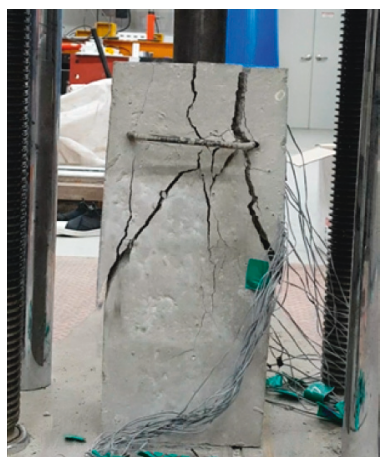

(b)

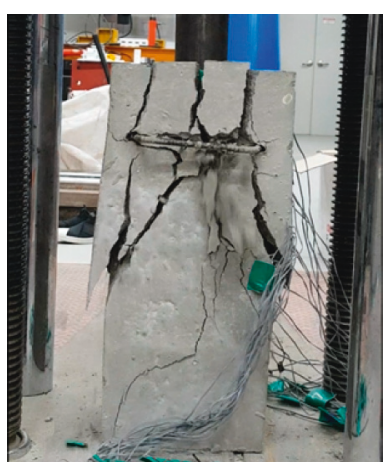

(c)

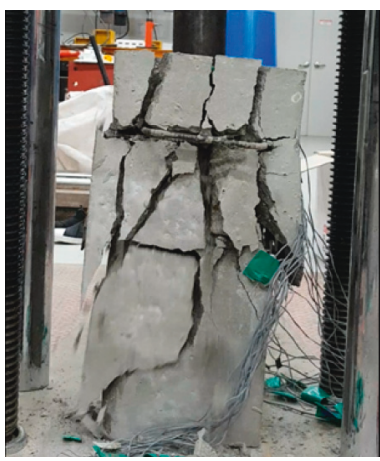

(d)

Figure 16: Failure in load transfer test specimens.

of the specimen surface. The pyramid shaped cracks were clearly observed and then the crack width increased. The final failure occurred as concrete spalling started. The cracks and failure patterns are similar, but more inclined cracks and 


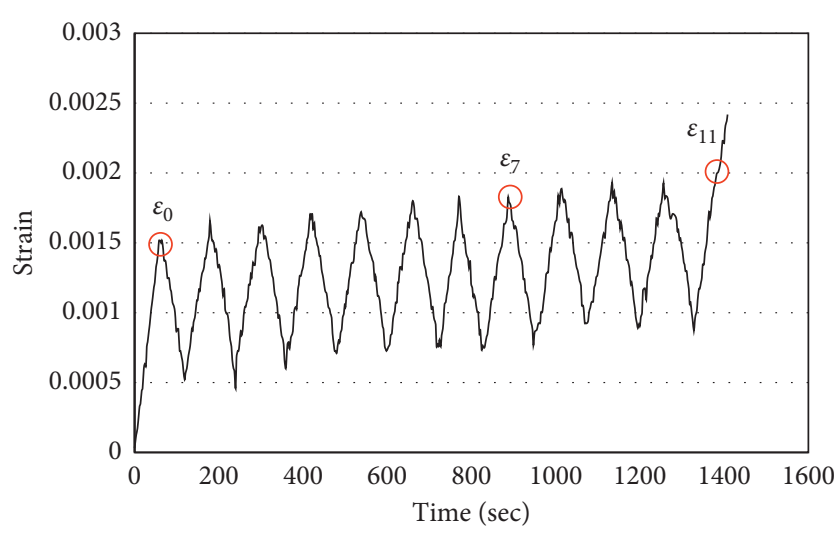

(a)

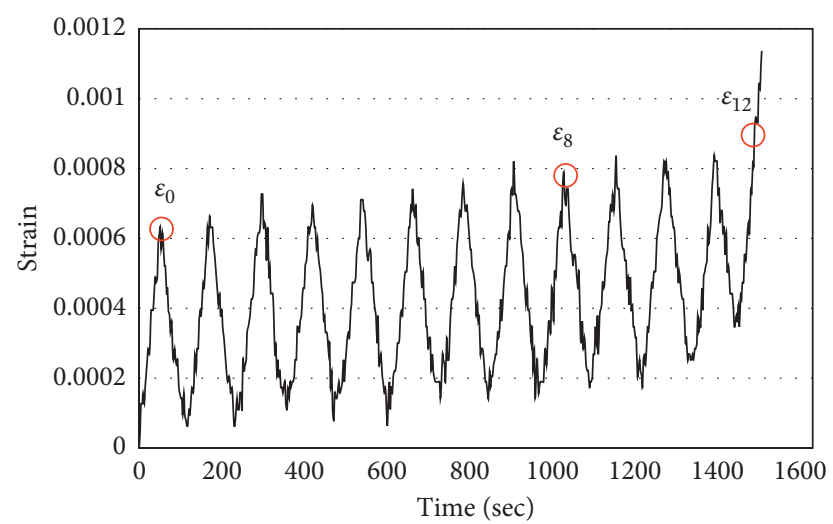

(c)

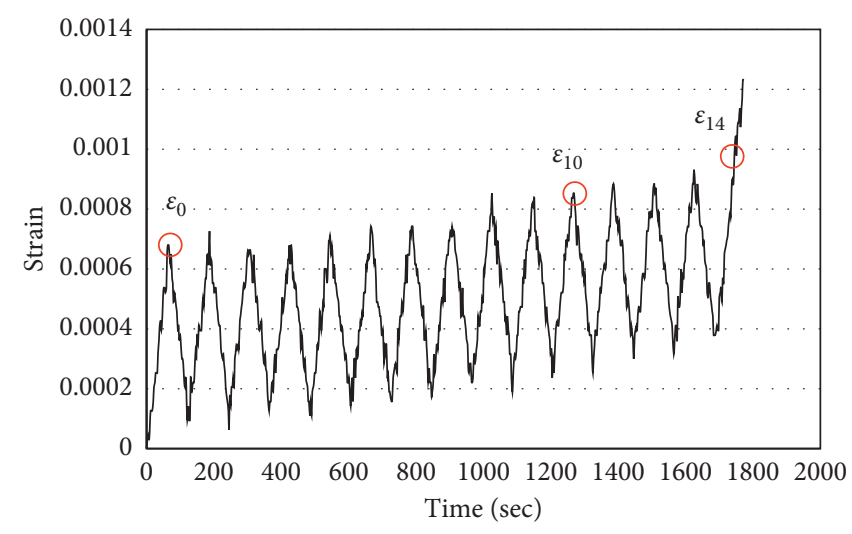

(b)

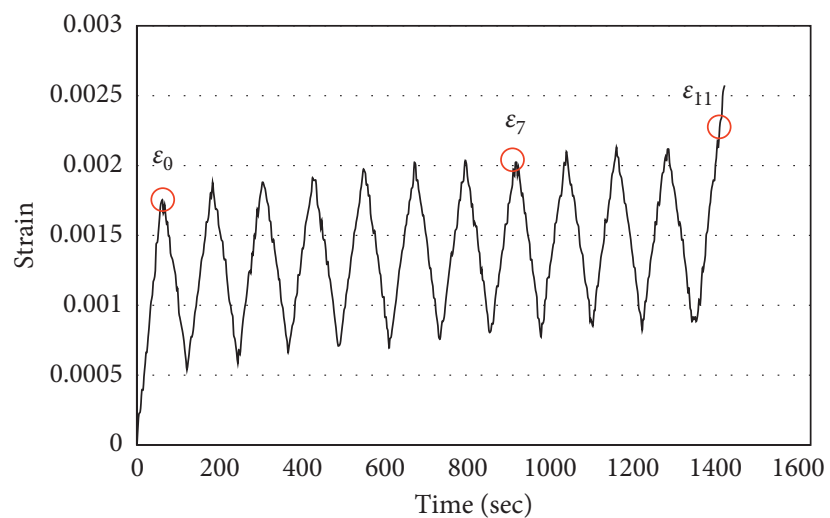

(d)

FIgURE 17: Crack widths in load transfer test specimens (gauge 5): (a) LT-A, (b) LT-B, (c) LT-C, and (d) LT-D.

TABLE 4: Ultimate load and strain in the load transfer test.

\begin{tabular}{|c|c|c|c|c|c|c|}
\hline Specimen & Min required load $\left(1.1 F_{p k}\right)$ & Maximum load $\left(F_{p}\right)(\mathrm{kN})$ & Last cycle & $1 / 3\left(\varepsilon_{n-4}-\varepsilon_{0}\right)$ & $\varepsilon_{n}-\varepsilon_{n-4}$ & Stabilization \\
\hline LT-A & & N.A. & 11 & 1.050.E-04 & 9.817.E- 05 & OK \\
\hline LT-B & $284 \mathrm{kN}$ & 881 & 14 & 5.789.E- 05 & $3.150 . E-05$ & OK \\
\hline LT-C & $284 \mathrm{KN}$ & 784 & 12 & 6.839.E- 05 & 1.583.E- 05 & OK \\
\hline LT-D & & 833 & 11 & 9.478.E- 05 & 7.883.E- 05 & OK \\
\hline
\end{tabular}

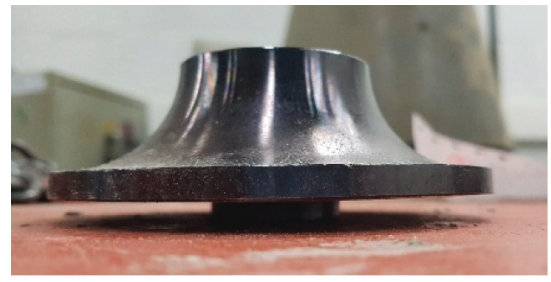

(a)

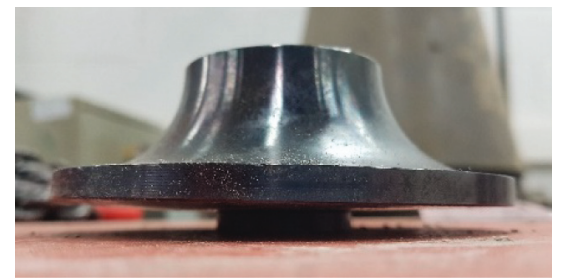

(b)

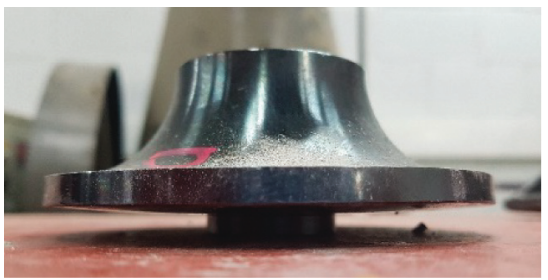

(c)

FIGURE 18: Deformation of anchorages: (a) LT-B, (b) LT-C, and (c) LT-D.

wider cracks were observed in the specimen with the conventional anchorage device.

Figure 21 shows comparisons of the strains along the tendon paths between the conventional and proposed anchorage devices, which had similar patterns. The strain was lower in both specimens, except near the anchorage device at the $75 \%$ of the maximum load. However, the strain increased rapidly when it reached the maximum load. The strains in the specimen with the conventional anchorage were greater than the one with the proposed anchorage. In the specimen with the proposed anchorage, the strain developed from the anchorage gently converged along the specimen unlike the 


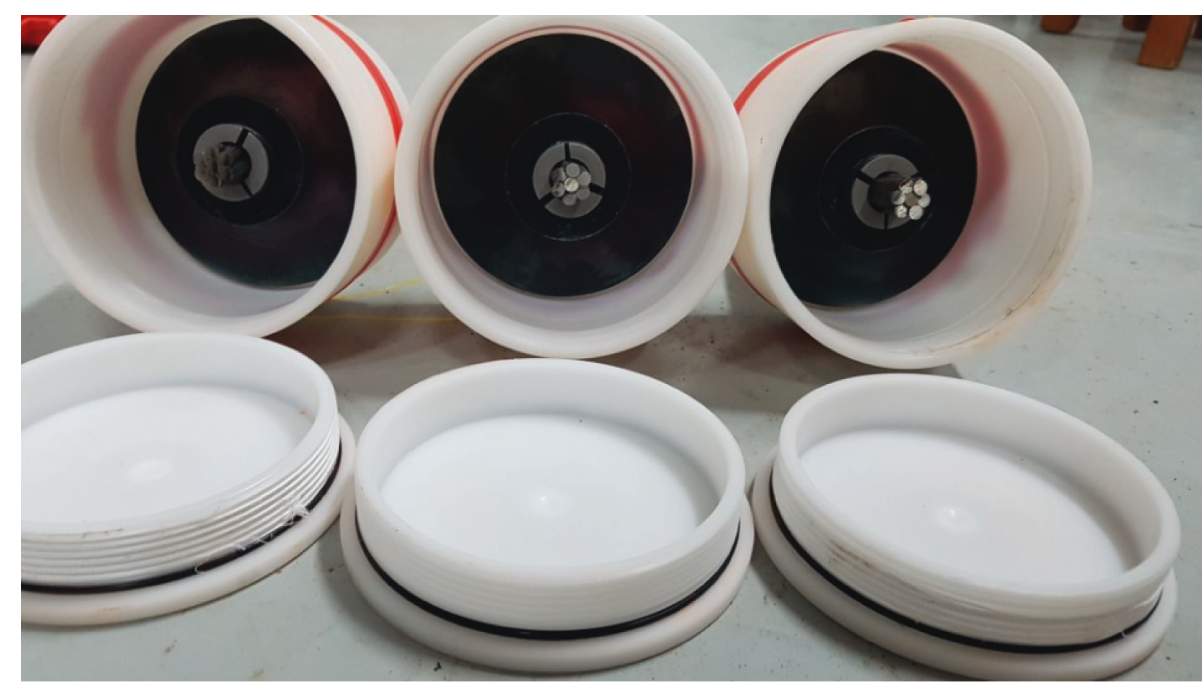

Figure 19: Results of the water tightness test.

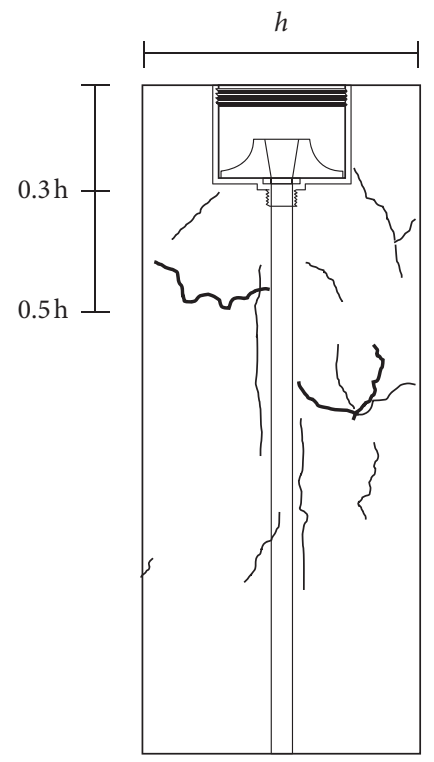

(a)

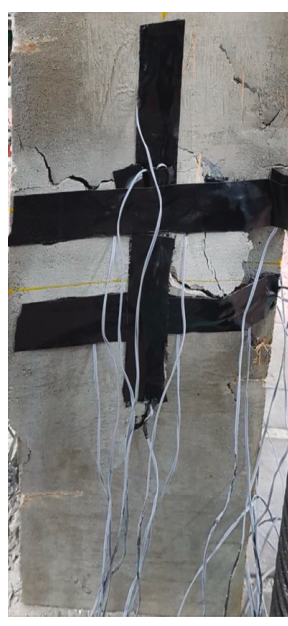

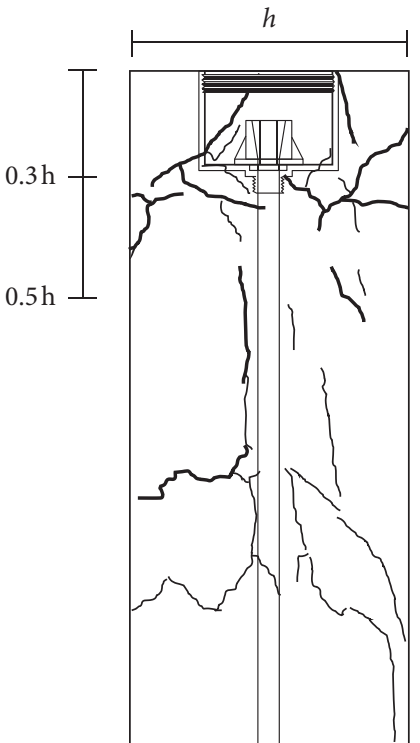

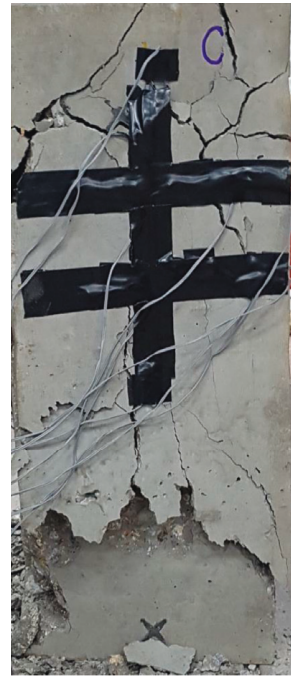

(b)

FIGURE 20: Crack pattern of bursting strength test: (a) circular anchorage and (b) rectangular anchorage.

conventional anchorage specimen. It is concluded that the stresses are better distributed in the specimen with the proposed anchorage.

\section{Conclusions}

In this paper, both analytical and experimental studies were performed to develop an effective anchorage system in terms of structural performance and water tightness. New anchorage details were proposed based on the finite element analysis, and the performance of the proposed anchorage was evaluated by means of static test, load transfer test, hydrostatic test, and bursting force test. The following conclusions have been drawn:
(1) The thickness of the anchor head, thickness of the cavity, radius of curvature between the cavity and the bearing plate, and thickness of the bearing plate were considered as variables in finite element analysis. Details of a circular anchorage for a single tendon were proposed based on the analysis results.

(2) The bursting stress of the proposed anchorage and a conventional rectangular anchorage was analytically compared. The bursting stress in the proposed anchorage was reduced by $50 \%$ compared with that of the rectangular anchorage. The location of maximum bursting stress in the proposed anchorage was 1.7 times that of the rectangular anchorage. The bursting stress is better distributed in the proposed anchorage than in the rectangular anchorage. 


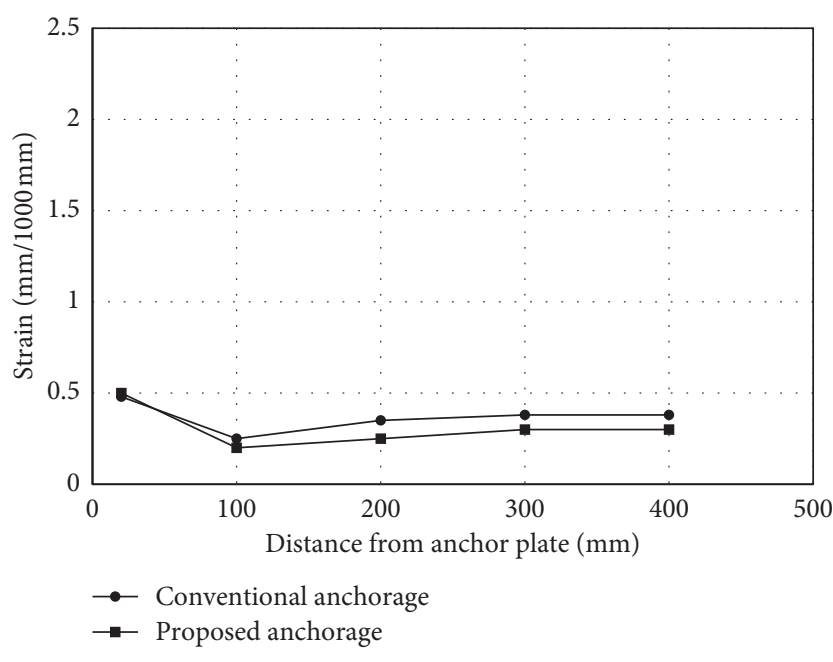

(a)

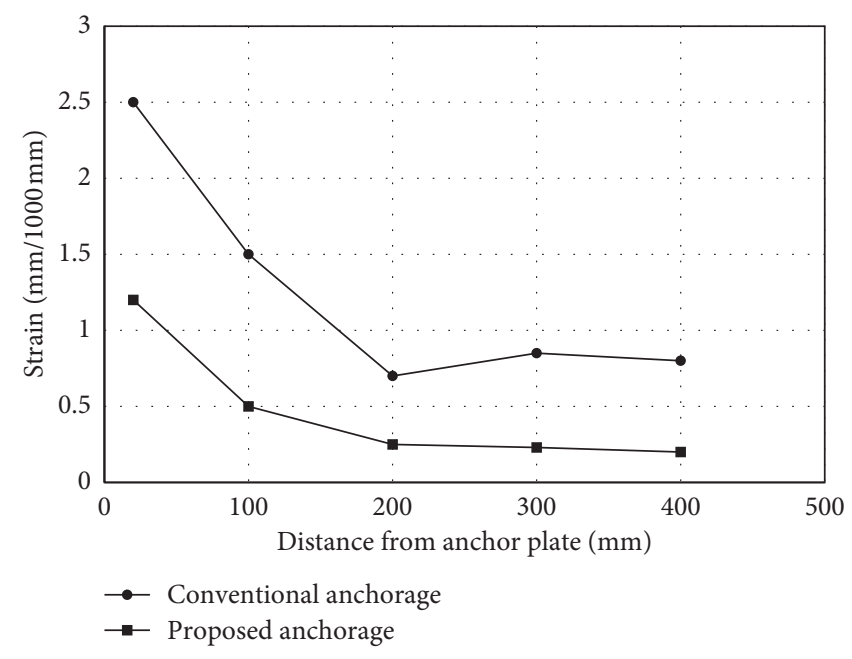

(b)

Figure 21: Result of the bursting strength test: (a) 75\% ultimate load and (b) ultimate load.

(3) The measured anchorage slip and stabilization satisfied ETAG recommendations. The proposed anchorage can provide stable assembly of anchorage devices. In the load transfer test, the maximum loading which is 1.1 times the ultimate strength of the tendon was applied without significant deformation of anchorage. Also, the proposed anchorage device imparted the anchorage system with improved water tightness. The experimental results show that the proposed circular anchorage device can improve the stress concentration.

(4) As a result of the bursting force test, the cracks and failure patterns of the two specimens were similar, but larger cracks and more concrete spalling were observed in the specimen with the conventional anchorage device. The specimen with the conventional anchorage shows larger strains than the specimen with the proposed anchorage.

\section{Notations}

$w_{n}:$ Crack width

$\varepsilon_{n}$ : Longitudinal and transverse strain

$n$ : Number of loading cycles.

\section{Data Availability}

The data used to support the findings of this study are available from the corresponding author upon request.

\section{Conflicts of Interest}

The authors declare that there are no conflicts of interest regarding the publication of this paper.

\section{Acknowledgments}

This work was supported by the National Research Foundation of Korea (NRF) grant funded by the Korea Government (MSIT) (NRF-2017R1A2B2005581).

\section{References}

[1] Y. Kwon, J. K. Kim, and J. M. Yang, "Development of efficient anchorage device and estimation of its bearing strength of posttensioning anchorage zone," Journal of Structural Engineering, vol. 144, no. 3, Article ID 04017219, 2018.

[2] K. Q. Walsh, R. L. Draginis, R. M. Estes, and Y. C. Kurama, "Effects of anchor wedge dimensional parameters on posttensioning strand performance," PCI Journal, vol. 60, no. 3, pp. 63-83, 2015.

[3] J.-K. Kim, J.-M. Yang, and Y. Kwon, "Influence of steel fiber and reinforcing details on the ultimate bearing strength of the post-tensioning anchorage zone," Structural Engineering and Mechanics, vol. 59, no. 5, pp. 867-883, 2016.

[4] K. Q. Walsh and Y. C. Kurama, "Effects of loading conditions on the behavior of unbonded post-tensioning strand-anchorage systems," PCI Journal, vol. 57, no. 1, pp. 76-96, 2012.

[5] ACI, ACI 423.4R-98: Corrosion and Repair of Unbonded Single Strand Tendons, ACI, Farmington Hills, MI, USA, 1998.

[6] A. J. Schokker, J. E. Breen, and M. E. Kreger, "Grouts for bonded post-tensioning in corrosive environments," $A C I$ Materials Journal, vol. 98, no. 4, pp. 296-305, 2001.

[7] H. Minh, H. Mutsuyoshi, and K. Niitani, "Influence of grouting condition on crack and load-carrying capacity of post-tensioned concrete beam due to chloride-induced corrosion," Construction and Building Materials, vol. 21, no. 7, pp. 1568-1575, 2007.

[8] F. Li, Y. Yuan, and C.-Q. Li, "Corrosion propagation of prestressing steel strands in concrete subject to chloride attack," Construction and Building Materials, vol. 25, no. 10, pp. 3878-3885, 2011.

[9] L. Wang, L. Dai, H. Bian, Y. Ma, and J. Zhang, "Concrete cracking prediction under combined prestress and strand corrosion," Structure and Infrastructure Engineering, vol. 15, no. 3, pp. 285-295, 2019.

[10] L. Dai, L. Wang, H. Bian, J. Zhang, J. X. Zhang, and Y. Ma, "Flexural capacity prediction of corroded prestressed concrete beams incorporating bond degradation," Journal of Aerospace Engineering, vol. 32, no. 4, Article ID 04019027, 2019. 
[11] F. L. Sorkin, "Positively retained cap for use on an encapsulated anchor of a post-tension anchor system," U.S. Patent and Trademark Office, Washington, DC, USA, US patent 7,424,792, 2008.

[12] J. R. Crigler and G. A. Hunsicker, "Encapsulated anchor devices, systems, and methods," U.S. Patent and Trademark Office, Washington, DC, USA, US patent 9,982,434, 2018.

[13] European Organization for Technical Approvals, ETAG 013: Guideline for European Technical Approval of Post-Tensioning Kits for Prestressing of Structures, European Organization for Technical Approvals, Brussels, Belgium, 2002.

[14] American Association of State Highway Transportation Officials (AASHTO), AASHTO LRFD Bridge Construction Specifications, American Association of State Highway Transportation Officials (AASHTO), Washington, DC, USA, 2nd edition, 2003.

[15] PTI, PTI T. A. B. 1-06: Post-tensioning Manual-Sixth Edition, Post-Tensioning Institute, Phoenix, AZ, USA, 2006.

[16] Joint ACI-ASCE Committee 423, ACI 423.7-07: Specification for Unbonded Single-Strand Tendons and Commentary, American Concrete Institute, Farmington Hills, MI, USA, 2007. 


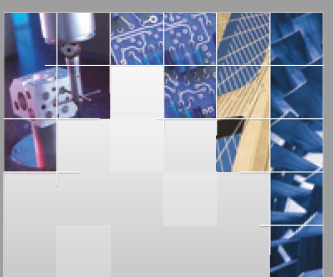

\section{Enfincering}
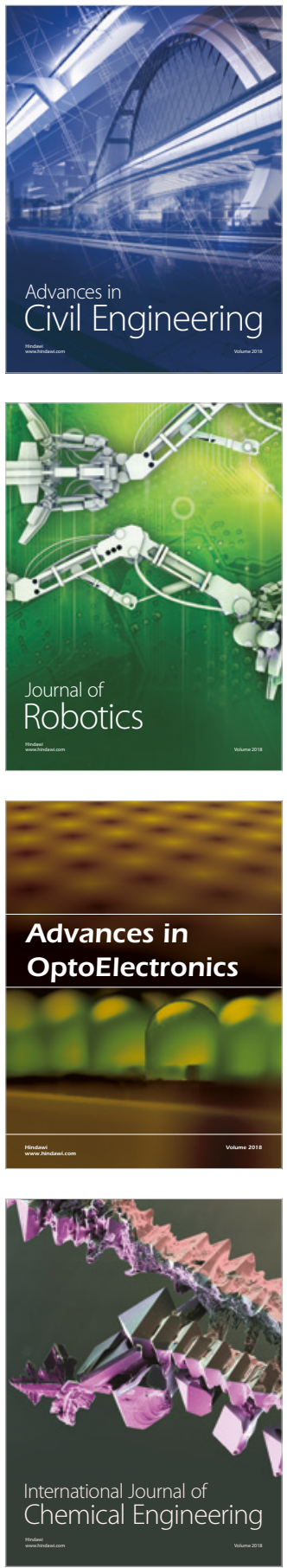

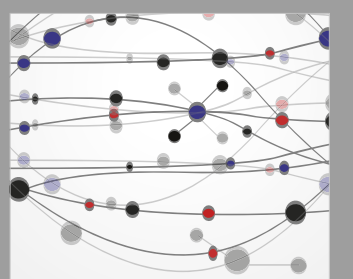

\section{Rotating \\ Machinery}

The Scientific World Journal

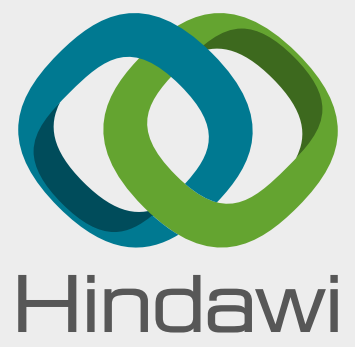

Submit your manuscripts at

www.hindawi.com
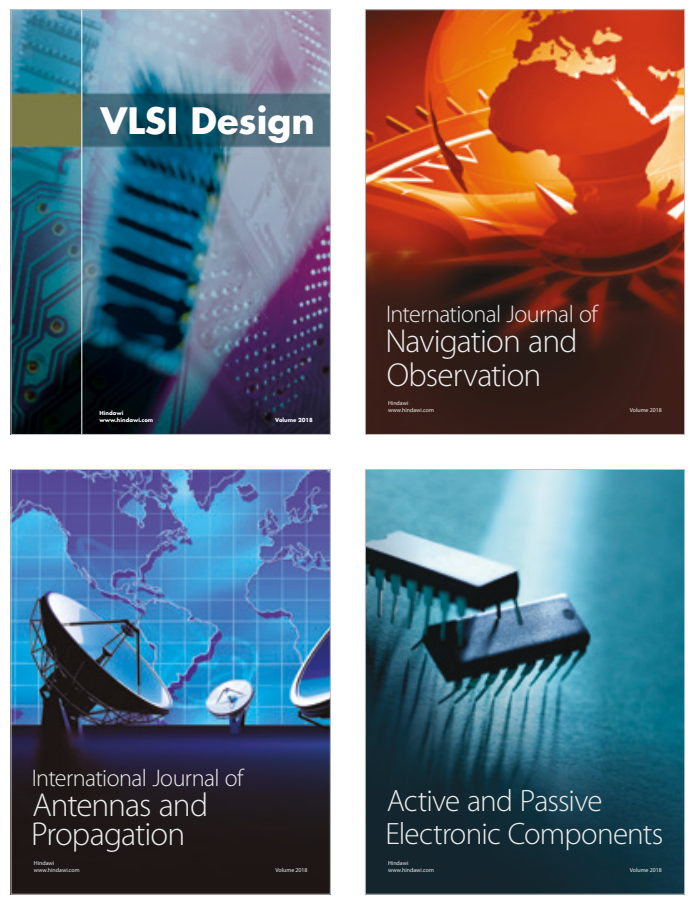
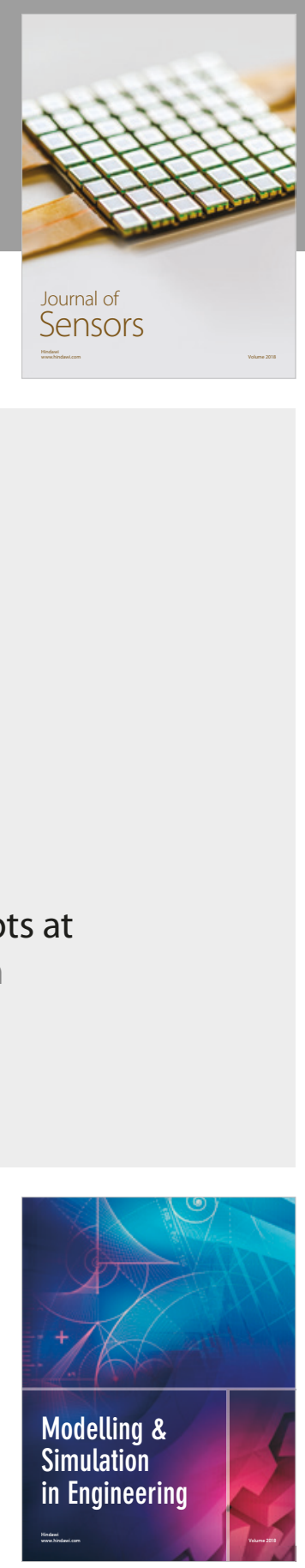

\section{Advances \\ Multimedia}
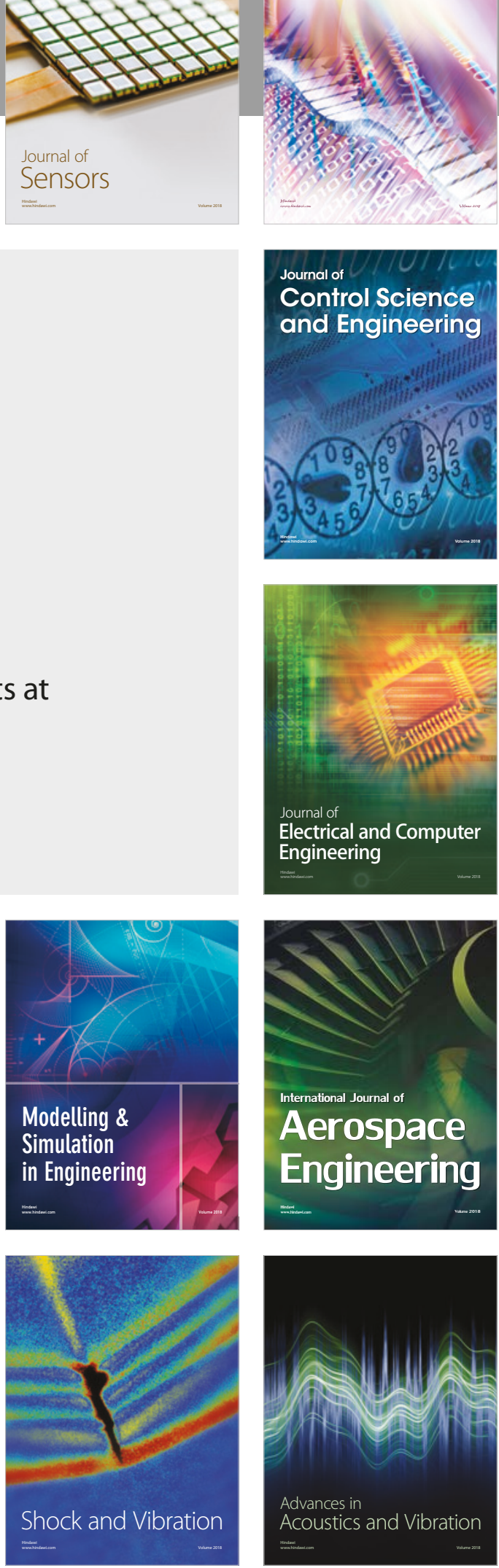